\title{
Flora das cangas da Serra dos Carajás, Pará, Brasil: Bixaceae
}

\author{
Flora of the cangas of Serra dos Carajás, Pará, Brazil: Bixaceae
}

Aluisio José Fernandes Júnior ${ }^{1,3}$ \& André dos Santos Bragança Gil ${ }^{2}$

\begin{abstract}
Resumo
Foram encontradas duas espécies de Bixaceae na Serra dos Carajás, Pará, Brasil: Bixa orellana e Cochlospermum orinocense. São apresentadas descrições morfológicas, ilustrações, comentários taxonômicos, distribuição geográfica e habitat de cada espécie.

Palavras-chave: Amazônia, Bixa, Cochlospermum, FLONA Carajás, taxonomia.
\end{abstract}

\begin{abstract}
Two species of Bixaceae were found in Serra dos Carajás, Pará state, Brazil: Bixa orellana and Cochlospermum orinocense. Morphological descriptions, illustration, taxonomic comments, geographical distribution and habitat of each species are presented.
\end{abstract}

Key words: Amazon, Bixa, Cochlospermum, FLONA Carajás, taxonomy.

\section{Bixaceae}

Bixaceae Kunth possui distribuição pantropical, apresentando quatro gêneros e 21 espécies (Stevens 2001; APG 2016). Os representantes da família apresentam hábito arbustivo a arbóreo; folhas alternas, simples ou compostas, estipuladas, inteiras, palmatissectas, palmatipartidas ou lobadas; inflorescência racemosa ou paniculada; flor com perianto pentâmero, com verticilos livres, imbricados na antese, estames numerosos e livres, anteras rimosas ou poricidas, ovário súpero, sincárpico, 2-5 carpelar; cápsula loculicida, sementes numerosas (adaptado de Poppendieck 1981; Bayer 2003; Poppendieck 2003).

No Brasil ocorrem dois gêneros e seis espécies, amplamente distribuídas, com todas as espécies presentes no domínio amazônico (BFG 2015), das quais duas foram registradas na Serra dos Carajás: Bixa orellana L. e Cochlospermum orinocense (Kunth) Steud.

\section{Chave de identificação dos gêneros de Bixaceae das cangas da Serra dos Carajás}

1. Folhas simples; indumento lepidoto com tricomas peltados nos ramos, pecíolos e lâminas foliares; pétalas alvas a rosadas; anteras com poros apicais elípticos; cápsula equinada, glabra; sementes obovoides a obpiriformes, glabras 1. Bixa

1'. Folhas compostas; indumento tomentoso com tricomas simples nos ramos, pecíolos e lâminas foliares; pétalas amareladas; anteras com poros apicais circulares; cápsula inerme, velutina; sementes cocleadas, lanosas 2. Cochlospermum

\section{Bixa Kunth}

O gênero Bixa, com cinco espécies, apresenta distribuição restrita a região Neotropical (Poppendieck 2003). No Brasil, o gênero está representado por três espécies, $B$. arborea Huber, $B$. excelsa Gleason \& Krukoff e B. orellana L. ocorrentes em todos os domínios fitogeográficos (BFG 2015). Bixa caracteriza-se pelo indumento lepidoto com tricomas peltados nos ramos, pecíolos e lâminas foliares, folhas simples com lâmina e margem inteiras, sépalas semelhantes, caducas na antese; ovário 2-carpelar, cápsula equinada (exceto

\footnotetext{
${ }^{1}$ Museu Paraense Emílio Goeldi, Campus de Pesquisa, Coord. Botânica, Prog. Capacitação Institucional, Av. Perimetral 1901, Terra Firme, 66077-830, Belém, PA, Brasil.

${ }^{2}$ Museu Paraense Emílio Goeldi, Campus de Pesquisa, Coord. Botânica, Av. Perimetral 1901, Terra Firme, 66077-830, Belém, PA, Brasil.

${ }^{3}$ Autor para correspondência: ajfernandesjunior@gmail.com
} 
em B. arborea Huber) e sementes glabras, com sarcotesta, frequentemente vermelho-alaranjada (Baer 1976; Poppendieck 1981; Christenhusz 2012). Para a Serra dos Carajás foi registrada apenas uma espécie: Bixa orellana.

\subsection{Bixa orellana L. Sp. Pl. 1: 512. 1753.}

Fig. 1a-g

Árvores 3-6 m alt.; indumento lepidoto, com tricomas peltados nos ramos, pecíolos e lâminas foliares; ramos cilíndricos, lenticelados, glabrescentes a lepidotos. Folhas simples, inteiras; pecíolos 1,9-8,2 cm compr., pulvinados nas extremidades; lâminas $6,8-18,9 \times 3,3-11,6 \mathrm{~cm}$, 5 -nervadas, ovadas a cordiformes, base truncada ou levemente cordada, face adaxial glabra, face abaxial lepidota, ápice acuminado, margem inteira. Inflorescências cimosas, terminais; pedicelo 0,5-1,6 cm compr., 5-glandular no ápice, glândulas elípticas a ovadas; sépalas 7-9 × 6-7 mm, ovadas, externamente lepidotas, internamente glabras; pétalas $1,6-3 \times 0,8-1,5 \mathrm{~cm}$, alvas a rosadas, obovadas, ápice arredondado, com tricomas peltados esparsos; estames numerosos, filetes 1-1,1 cm compr., livres, anteras 1-1,5 mm compr., poros 2, apicais, elípticos; ovário 2-carpelar, estilete 1 , estigma capitado; cápsula loculicida, obovoide, equinada, glabra; sementes ca. $5 \mathrm{~mm}$ compr., obovoides a obpiriformes, papilosas, sarcotesta vermelho-alaranjada.

Material selecionado: Parauapebas [Marabá], Serra Norte, N1, 2.VI.1986, fr., M.P.M. Lima et al. 104 (MG).

Bixa orellana caracteriza-se pelas glândulas conspícuas e esverdeadas no ápice do pedicelo, frutos equinados, deiscentes e glabros, e pelas sementes com sarcotesta vermelho-alaranjada (Baer 1976; Christenhusz 2012). Devido sua coloração intensa, suas sementes são bastante utilizadas na culinária e na indústria cosmética (Steyermark \& Holst 1997).

Espécie Neotropical, distribuída do México até a Argentina (Christenhusz 2012). No Brasil, a espécie apresenta ampla distribuição, ocorrendo em todos os estados (BFG 2015). Na Serra dos Carajás foi registrada na Serra Norte: N1, em mata ciliar.

\section{Cochlospermum Kunth}

O gênero Cochlospermum possui 14 espécies com distribuição pantropical, sendo encontrado nas Américas, África, Ásia e Austrália (Poppendieck 1981; Cowie \& Kerrigan 2015). No Brasil, o gênero está representado por três espécies: $C$. orinocense (Kunth) Steud., C. regium (Schrank) Pilg. e $C$. vitifolium (Willd.) Spreng. Espécies do gênero ocorrem em quase todos os estados, habitando principalmente cerrado, savanas amazônicas e ambientes abertos (BFG 2015). Cochlospermum caracteriza-se por apresentar folhas decíduas, palmatissectas, palmatipartidas,lobadas ou digitadas, cálice persistente com sépalas desiguais (duas externas menores e três internas maiores), ovário 3-5-carpelar (Poppendieck 2003). Para a Serra dos Carajás foi registrada apenas uma espécie: Cochlospermum orinocense.

2.1. Cochlospermum orinocense (Kunth) Steud., Nomencl. Bot. (ed. 2) 1: 393. 1840.

Figs. 1h-m

Árvores 7-15 m alt.; indumento pubescente a tomentoso, com tricomas simples nos ramos, pecíolos, lâminas foliares e frutos; ramos cilíndricos, lenticelados, glabrescentes a pubescentes. Folhas compostas, 5-6-folioladas; pecíolos 16,8-22,9 cm compr., não pulvinados nas extremidades; peciólulos 3-5 mm compr.; lâminas 8-13,7 × 4,8-5,9 cm, 1-nervadas, elípticas, base cuneada a arredondada, face adaxial glabra, face abaxial pubescente, ápice agudo, margem inteira. Inflorescências cimosas, terminais; pedicelo 1-1,9 cm compr., glândulas no ápice ausentes; sépalas 11-16 × 5-9 mm, ovadas a obovadas, externamente tomentosas, internamente pubérulas; pétalas $3,8-5,7 \times 2,5-3,8 \mathrm{~cm}$, amareladas, obovadas, ápice emarginado, com tricomas simples esparsos; estames numerosos, filetes $0,8-1 \mathrm{~cm}$ compr., livres, anteras 3-3,5 mm compr., poros 2, apicais, circulares; ovário 3 -carpelar, estilete 1 , estigma agudo; cápsula loculicida, obpiriforme, inerme, velutina; sementes 5-7 mm compr., cocleadas, lanosas, com tricomas simples avermelhados, ca. $5 \mathrm{~mm}$ compr.

Material examinado: Parauapebas, Serra Norte, N3, 6²4'00'S, 50¹8'56”, 6.VII.2014, fl., R.S. Santos et al. 228 (MG). Canaã dos Carajás, Serra Sul, Corpo A, $6^{\circ} 18^{\prime} 38^{\prime \prime}$ 'S, 502'72"'W, 29.VI.2010, fl. e fr., A.J. Arruda et al. 283 (BHCB).

Material adicional examinado: BRASIL. PARÁ: Santarém, Porto Novo, 5.XII.1978, fr., M.G.A. Lobo et al. 179 (MG).

Cochlospermum orinocense caracteriza-se pelas folhas compostas, pecíolos longos (até $25 \mathrm{~cm}$ compr.), anteras com dois poros apicais circulares e cápsula ereta obpiriforme (Poppendieck 1980). Esta é a única espécie do gênero ocorrente no Brasil, que apresenta folhas compostas e anteras com dois poros apicais (vs. folhas simples e anteras com poro único). 


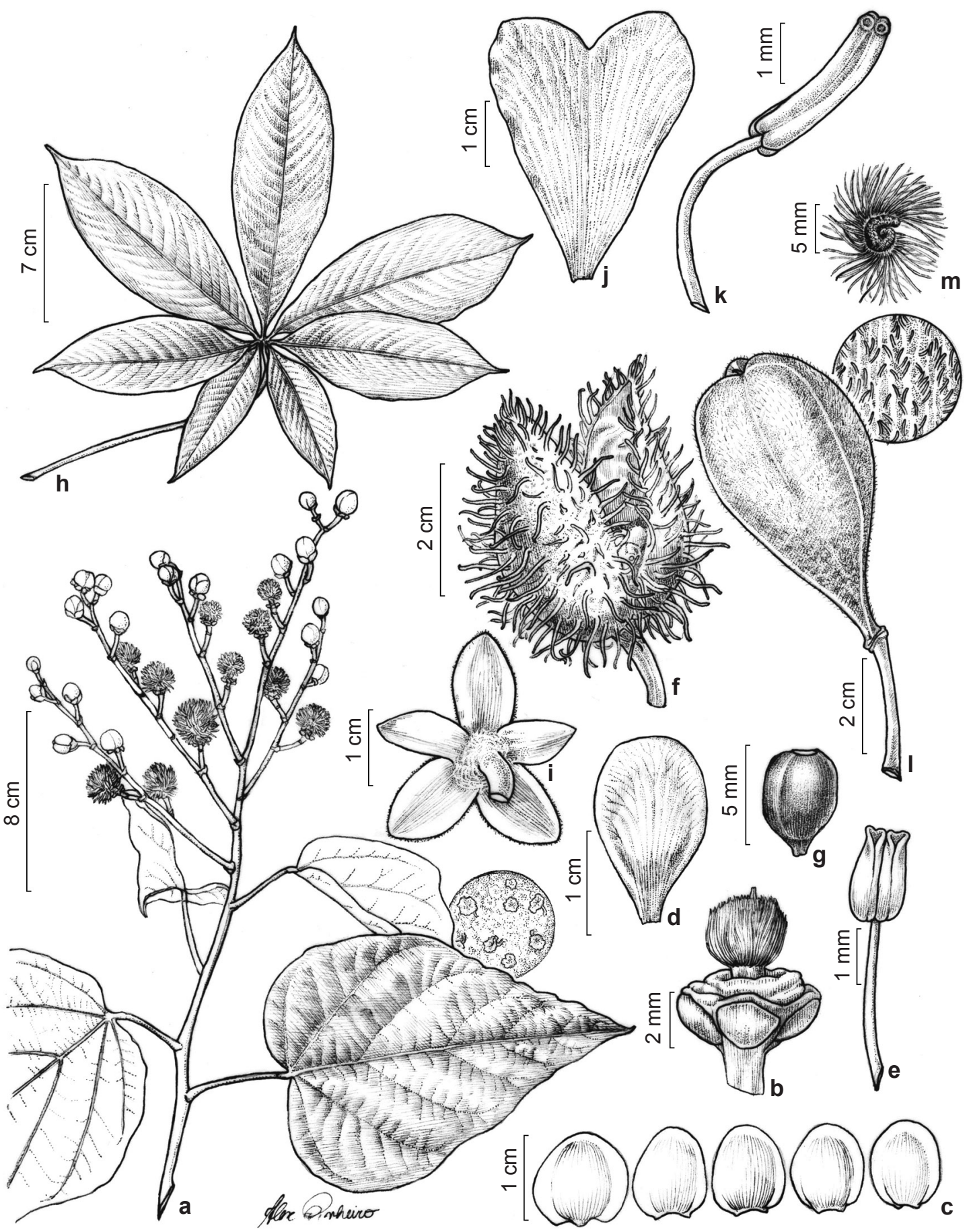

Figura 1 - a-g. Bixa orellana - a. ramo florífero; b. glândulas no ápice do pedicelo, perianto removido; c. sépalas, vista abaxial; d. pétala, vista abaxial; e. estame; f. fruto; g. semente. h-m. Cochlospermum orinocense - h. folha; i. sépalas, vista abaxial; j. pétala; k. estame; 1. fruto, detalhes do indumento; m. semente. (a-e. M.G. Silva 3050; f-g. M.F.F. Silva 1396; h-k. C.R. Sperling 6166; 1-m. M.G.A. Lobo 179). Ilustração: Alex Pinheiro.

Figure 1 - a-g. Bixa orellana - a. flowering branch; b. glands at the apex of the pedicel, perianth removed; c. sepals, abaxial view; d. petal, abaxial view; e. stamen; f. fruit; g. seed. h-m. Cochlospermum orinocense - h.leaf; i. sepals, abaxial view; j. petal, abaxial view; k. stamen; 1. fruit, details of the indumentum; m. seed. (a-e. M.G. Silva 3050; f-g. M.F.F. Silva 1396; h-k. C.R. Sperling 6166; 1-m. M.G.A. Lobo 179). Ilustration: Alex Pinheiro. 
Espécie Neotropical, distribuída no Panamá, Peru, Venezuela e Brasil (Poeppendick 1981). No Brasil, a espécie apresenta distribuição na região Norte (Acre, Amapá, Amazonas, Pará, Rondônia, Roraima), Nordeste (Maranhão) e Centro-Oeste (Mato Grosso) (BFG 2015). Na Serra dos Carajás foi registrada na Serra Norte: N3 e Serra Sul: S11A, na borda de mata baixa sobre a canga.

\section{Agradecimentos}

Agradecemos ao Museu Paraense Emílio Goeldi e ao Instituto Tecnológico Vale, a estrutura e apoio. Aos curadores dos herbários BHCB, IAN e MG, a disponibilização de material para a análise. Ao Dr. Pedro Viana e à Dra. Ana Maria Giulietti, coordenadores do projeto "Flora de Carajás", o convite. Ao CNPq, a bolsa do Programa de Capacitação Institucional (MPEG/MCTI) concedida à AJFJ. Ao projeto objeto do convenio MPEG/ITV/FADESP (01205.000250/2014-10) e ao projeto aprovado pelo $\mathrm{CNPq}$ (processo 455505/2014-4), o financiamento. Ao Alex Pinheiro, a confecção da ilustração.

\section{Referências}

APG (2016) An update of the Angiosperm Phylogeny Group classification for the orders and families of flowering plants: APG IV. Botanical Journal of the Linnean Society 181: 1-20.
Baer DF (1976) Systematics of the genus Bixa and geography of the cultivated annatto tree. $\mathrm{PhD}$ Thesis. University of California, Los Angeles. 240p.

Bayer C (2003) Diegodendraceae. In: Kubitzki K \& Bayer C (eds.) The families and genera of vascular plants. Springer, Berlin. Pp. 175-177.

BFG - The Brazil Flora Group (2015) Growing knowledge: an overview of seed plant diversity in Brazil. Rodriguésia 66: 1085-1113.

Christenhusz MJM (2012) Bixaceae. In: Davidse G, Sousa M \& Chater AO (eds.) Flora Mesoamericana. Cidade do Universidad Nacional Autónoma de México, México. Pp. 1-4.

Cowie ID \& Kerrigan RA (2015) A new species of Cochlospermum (Bixaceae) from Arnhem Land, Northern Territory, Australia. Telopea 18: 135-140.

Poeppendieck HH (1981) Cochlospermaceae. Flora Neotropica Monograph 27: 1-33.

Poeppendieck HH (2003) Bixaceae. In: Kubitzki K \& Bayer C (eds.) The families and genera of vascular plants. Springer, Berlin. Pp. 33-35.

Stevens PF [2001 em diante]. Angiosperm Phylogeny Website. Version 12, July 2012 [and more or less continuously updated since]. Disponível em <http://www.mobot.org/MOBOT/research/ APweb/>. Acesso em 23 março 2017.

Steyermark JA \& Holst BK (1997) Bixaceae. In: Berry PE, Holst BK \& Yatskievych K (eds.) Flora of the Venezuelan Guayana. Vol. 3: AraliaceaeCactaceae. Missouri Botanical Garden Press, St. Louis. Pp. 492-495.

\section{Lista de exsicatas}

Arruda AJ 283 (2.1). Lima MPM 104 (1.1). Lobo MGA 179 (2.1). Santos RS 228 (2.1). Secco R 110 (1.1). Silva MFF 1396 (1.1). Silva MG 3050 (1.1). Sperling CR 6166 (2.1). 